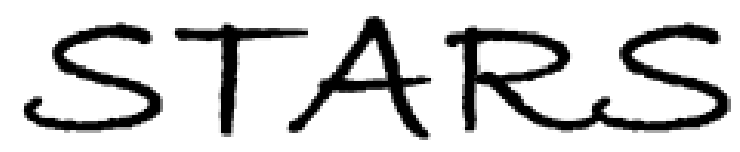

University of Central Florida

STARS

$1-1-2011$

\title{
ZnO homojunction photodiodes based on Sb-doped p-type nanowire array and n-type film for ultraviolet detection
}

Guoping Wang

Sheng Chu

Ning Zhan

Yuqing Lin

University of Central Florida

Leonid Chernyak

University of Central Florida

See next page for additional authors

Find similar works at: https://stars.library.ucf.edu/facultybib2010

University of Central Florida Libraries http://library.ucf.edu

This Article is brought to you for free and open access by the Faculty Bibliography at STARS. It has been accepted for inclusion in Faculty Bibliography 2010 s by an authorized administrator of STARS. For more information, please contactSTARS@ucf.edu.

\section{Recommended Citation}

Wang, Guoping; Chu, Sheng; Zhan, Ning; Lin, Yuqing; Chernyak, Leonid; and Liu, Jianlin, "ZnO homojunction photodiodes based on Sb-doped p-type nanowire array and n-type film for ultraviolet detection" (2011).

Faculty Bibliography 2010s. 2069.

https://stars.library.ucf.edu/facultybib2010/2069

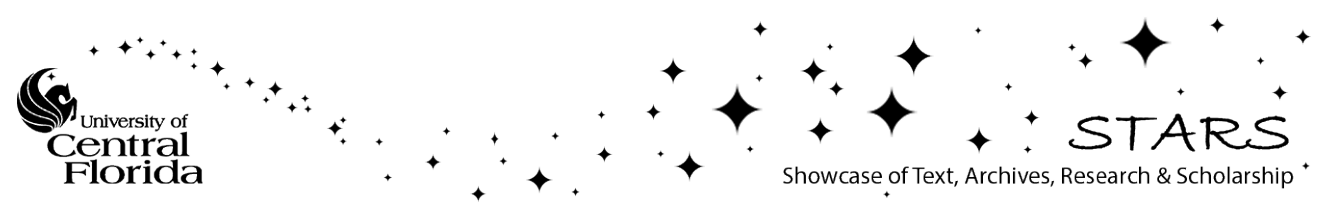


Authors

Guoping Wang, Sheng Chu, Ning Zhan, Yuqing Lin, Leonid Chernyak, and Jianlin Liu 


\section{ZnO homojunction photodiodes based on Sb-doped p-type nanowire array and n-type film for ultraviolet detection}

Cite as: Appl. Phys. Lett. 98, 041107 (2011); https://doi.org/10.1063/1.3551628

Submitted: 23 November 2010 . Accepted: 13 January 2011 . Published Online: 28 January 2011

Guoping Wang, Sheng Chu, Ning Zhan, Yuqing Lin, Leonid Chernyak, and Jianlin Liu

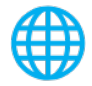

\section{ARTICLES YOU MAY BE INTERESTED IN}

Homojunction photodiodes based on Sb-doped $p$-type $\mathrm{ZnO}$ for ultraviolet detection

Applied Physics Letters 88, 092103 (2006); https://doi.org/10.1063/1.2178470

Opto-electrical properties of Sb-doped p-type ZnO nanowires

Applied Physics Letters 104, 111909 (2014); https://doi.org/10.1063/1.4869355

ZnO nanowires array $p-n$ homojunction and its application as a visible-blind ultraviolet photodetector

Applied Physics Letters 96, 053102 (2010); https://doi.org/10.1063/1.3299269

\section{Applied Physics Reviews}

Now accepting original research 


\title{
ZnO homojunction photodiodes based on Sb-doped p-type nanowire array and $n$-type film for ultraviolet detection
}

\author{
Guoping Wang, ${ }^{1}$ Sheng Chu, ${ }^{1}$ Ning Zhan, ${ }^{1}$ Yuqing Lin, ${ }^{2}$ Leonid Chernyak, ${ }^{2}$ and \\ Jianlin Liu ${ }^{1, a)}$ \\ ${ }^{1}$ Department of Electrical Engineering, Quantum Structures Laboratory, University of California \\ at Riverside, Riverside, California 92521, USA \\ ${ }^{2}$ Department of Physics, University of Central Florida, Orlando, Florida 32816-2385, USA
}

(Received 23 November 2010; accepted 13 January 2011; published online 28 January 2011)

\begin{abstract}
$\mathrm{ZnO}$ p-n homojunctions based on Sb-doped p-type nanowire array and n-type film were grown by combining chemical vapor deposition (for nanowires) with molecular-beam epitaxy (for film). Indium tin oxide and $\mathrm{Ti} / \mathrm{Au}$ were used as contacts to the $\mathrm{ZnO}$ nanowires and film, respectively. Characteristics of field-effect transistors using $\mathrm{ZnO}$ nanowires as channels indicate p-type conductivity of the nanowires. Electron beam induced current profiling confirmed the existence of $\mathrm{ZnO}$ p-n homojunction. Rectifying I-V characteristic showed a turn-on voltage of around $3 \mathrm{~V}$. Very good response to ultraviolet light illumination was observed from photocurrent measurements. (C) 2011 American Institute of Physics. [doi:10.1063/1.3551628]
\end{abstract}

$\mathrm{ZnO}$ has a wide band gap of $3.37 \mathrm{eV}$ and a large exciton binding energy of $60 \mathrm{meV}$ at room temperature, ${ }^{1,2}$ which make it a promising candidate for optoelectronic devices such as blue-light emitting diodes, ${ }^{3,4}$ ultraviolet (UV) laser diodes, ${ }^{5-7}$ and photodiodes. ${ }^{8-10}$ Recently, there have been tremendous interests in $\mathrm{ZnO}$ nanowire arrays. Although heterojunction optoelectronic devices ${ }^{11-13}$ have been fabricated based on vertically aligned $\mathrm{ZnO}$ nanowire arrays, there still lacks the homojunction type devices based on p-type nanowire array/n-type $\mathrm{ZnO}$ film. It is well known that one of the biggest challenges toward good $\mathrm{ZnO}$-based optoelectronic devices is the difficulty of reliably fabricating p-type $\mathrm{ZnO}$ due to the self-compensating effect from native defects (for example, oxygen vacancy $\mathrm{V}_{\mathrm{o}}$ and zinc interstitial $\mathrm{Zn}_{\mathrm{i}}$ ) and/or $\mathrm{H}$ incorporation. ${ }^{14}$ Nevertheless, there has already been a great deal of efforts on the fabrication of p-type $\mathrm{ZnO}$ by doping group $\mathrm{V}$ elements, such as $\mathrm{N}, \mathrm{P}$, and As. ${ }^{15-17}$ Previously, our group showed that $\mathrm{Sb}$, another group $\mathrm{V}$ element, is an effective dopant for reproducible p-type $\mathrm{ZnO}$ thin films ${ }^{18}$ on $\mathrm{Si}$ and sapphire substrates. Heterojunction ${ }^{8}$ and homojunction ${ }^{9}$ light emitting diodes as well as photodiodes based on these films were achieved. In this study, we report $\mathrm{ZnO}$ p-n homojunctions based on Sb-doped p-type $\mathrm{ZnO}$ nanowire arrays grown by chemical vapor deposition (CVD) on n-type $\mathrm{ZnO}$ films on sapphire substrates grown by molecular-beam epitaxy (MBE). The homojunction diode exhibits a clear rectification characteristic as well as very good ultraviolet light absorption characteristics.

The device fabrication process of the p-type $\mathrm{ZnO}$ nanowire/n-type $\mathrm{ZnO}$ film structure is described as follows. A highly oriented vertical $\mathrm{ZnO}$ nanowire array was synthesized via seed growth method. ${ }^{19}$ First, n-type $\mathrm{ZnO}$ seed film, which also acted as n-type component of the junction, was grown on a 2 in. c-plane sapphire substrate using plasmaassisted MBE. The growth process began with a thin $\mathrm{MgO} /$ $\mathrm{ZnO}$ buffer layer of less than $10 \mathrm{~nm}$ at a growth temperature of $550{ }^{\circ} \mathrm{C}$ for improving the subsequent $\mathrm{ZnO}$ film quality. Then the seed $\mathrm{ZnO}$ film was grown at $700{ }^{\circ} \mathrm{C}$ for $5 \mathrm{~h}$, yield-

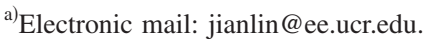

ing a total thickness of around $1050 \mathrm{~nm}$. Elemental $\mathrm{Zn}$ was evaporated at an effusion cell temperature of $360^{\circ} \mathrm{C}$. The oxygen plasma was generated using a radio-frequency plasma source. The oxygen flow rate was kept at $5 \mathrm{sccm}$. Hall effect measurements were carried out on the MBEgrown $\mathrm{ZnO}$ thin film. The film was found to have n-type conductivity with an electron concentration of 3.74 $\times 10^{17} \mathrm{~cm}^{-3}$, a mobility of $23.04 \mathrm{~cm}^{2} \mathrm{~V}^{-1} \mathrm{~s}^{-1}$, and a resistivity of $0.73 \Omega \mathrm{cm}$, respectively. The $\mathrm{ZnO}$ seed film was partially covered for exposing the film for later n-type contact deposition and then subsequently transferred into a quartz tube furnace system. The growth of nanowire array was carried out at $650{ }^{\circ} \mathrm{C}$ for $15 \mathrm{~min}$ with a gas flow of 1000 sccm nitrogen and $200 \mathrm{sccm}$ mixture gas of argon/oxygen (99.5:0.5). A Zn powder source (99.999\%) in a glass bottle was placed in the center of the quartz tube. At the place of $\sim 5 \mathrm{~cm}$ upstream to the $\mathrm{Zn}$ powder source, $\mathrm{Sb}$ powder (99.99\%) was placed in an open glass boat. The $\mathrm{ZnO}$ seed film was kept around $10 \mathrm{~cm}$ away from the $\mathrm{Zn}$ source on the downstream side. After a vertical nanowire array was achieved in CVD, polymethyl-methacrylate (PMMA) was spun on the sample to separate the bottom $\mathrm{ZnO}$ film and the subsequent top indium tin oxide (ITO) contact layer. The spin speed was $2000 \mathrm{rpm}$ for $30 \mathrm{~s}$, and this process was repeated for five times. After the sample was dried, a thin layer of ITO was sputtered by a sputter evaporator on the top of $\mathrm{ZnO}$ nanowire array. The sputtering process was performed at room temperature and the pressure was maintained at $10^{-2}$ Torr. The sputtering power and time were $180 \mathrm{~W}$ and $10 \mathrm{~min}$, respectively. After the growth of ITO, acetone was used to remove the PMMA layer. The device was finished by depositing $\mathrm{Ti} / \mathrm{Au}(20 \mathrm{~nm} / 100 \mathrm{~nm})$ on the n-type $\mathrm{ZnO}$ film using an electron-beam (e-beam) evaporator and rapidly annealed under $600{ }^{\circ} \mathrm{C}$ for $1 \mathrm{~min}$ to improve conductivity. Another low-resistant ITO glass slide was placed on the top of the $\mathrm{ZnO}$ nanowire array when $\mathrm{I}-\mathrm{V}$ and photoresponse characteristics were measured. Figure 1 shows a schematic diagram of the device.

Figures 2(a) and 2(b) show scanning electron microscopy (SEM) images of the nanowire array from the top and 


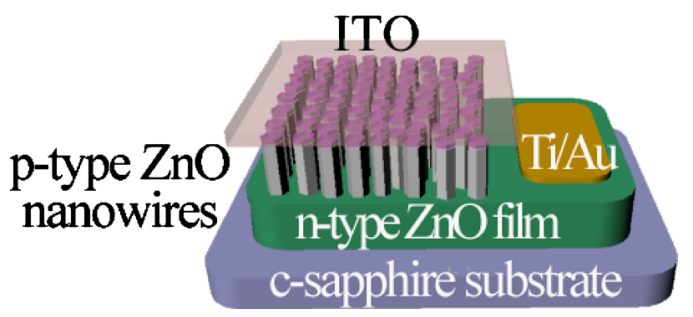

FIG. 1. (Color online) Schematic view of the photodetector device, which consists of $\mathrm{ZnO}$ thin film on c-sapphire substrate, vertically aligned $\mathrm{ZnO}$ nanowires, ITO contacts, and Ti/Au contacts.

the side, respectively. Typical wurtzite hexagonal structure $\mathrm{ZnO}$ nanowires are evident. The length and diameter of the $\mathrm{ZnO}$ nanowires are on average $3 \mu \mathrm{m}$ and $150 \mathrm{~nm}$, respectively. The single-crystalline nature of the $\mathrm{ZnO}$ nanowires is confirmed by high-resolution transmission electron microscopy (TEM) analysis, as shown in Fig. 2(c) and by the selected area electron diffraction (SAED) pattern [Fig. 2(d)].

Figure 3(a) shows spectrum of the electron beam induced current (EBIC) profiling of the homojunction between the $\mathrm{ZnO}$ nanowires and $\mathrm{ZnO}$ film superimposed on the sideview SEM image of the device. As a versatile tool, EBIC was widely used to identify buried junctions in semiconductors, including characterization of $\mathrm{ZnO}$ thin film $\mathrm{p}-\mathrm{n}$ junctions ${ }^{20}$ and silicon nanowire p-n junctions. ${ }^{21}$ In the experiment, electron-hole pairs are generated by electron beam irradiation. Then they are separated by built-in electric field in the p-n junction depletion region and collected by an external amplifier. Here, an accelerating voltage of $30 \mathrm{kV}$ was applied, corresponding to the electron penetration depth of $1.5 \mu \mathrm{m}$. Silver paste instead of ITO glass was used as contact to the p-type nanowires for facilitating the EBIC experiment. As seen from Fig. 3(a), an EBIC signal forms a peak on the thin film/nanowire junction, indicating the formation of $\mathrm{p}-\mathrm{n}$ junction. The second peak on the right is due to the formation of the nanowire/ITO/silver paste semiconductormetal junction.

The p-type conductivity of the Sb-doped $\mathrm{ZnO}$ nanowires can also be proved by field-effect measurement. $\mathrm{ZnO}$ nanowire field-effect transistors (NWFETs) were fabricated by standard photolithography. Sb-doped $\mathrm{ZnO}$ nanowires were transferred to a $\mathrm{p}^{+}$-silicon wafer with a $300 \mathrm{~nm}$ thick silicon oxide on the surface. Microcontact windows were defined on the ends of the nanowires, then Ni/Au $(20 \mathrm{~nm} / 100 \mathrm{~nm})$ elec-

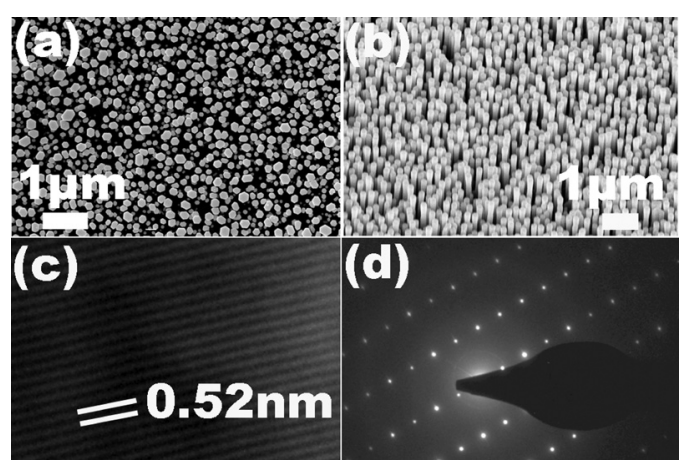

FIG. 2. (a) Top-view and (b) side-view SEM images of as-grown p-type $\mathrm{ZnO}$ nanowires. (c) High-resolution TEM image of a single nanowire. The lattice spacing between two atomic layers is measured to be $0.52 \mathrm{~nm}$. (d) SAED pattern, indicating the single-crystalline characteristic of the nanowire.
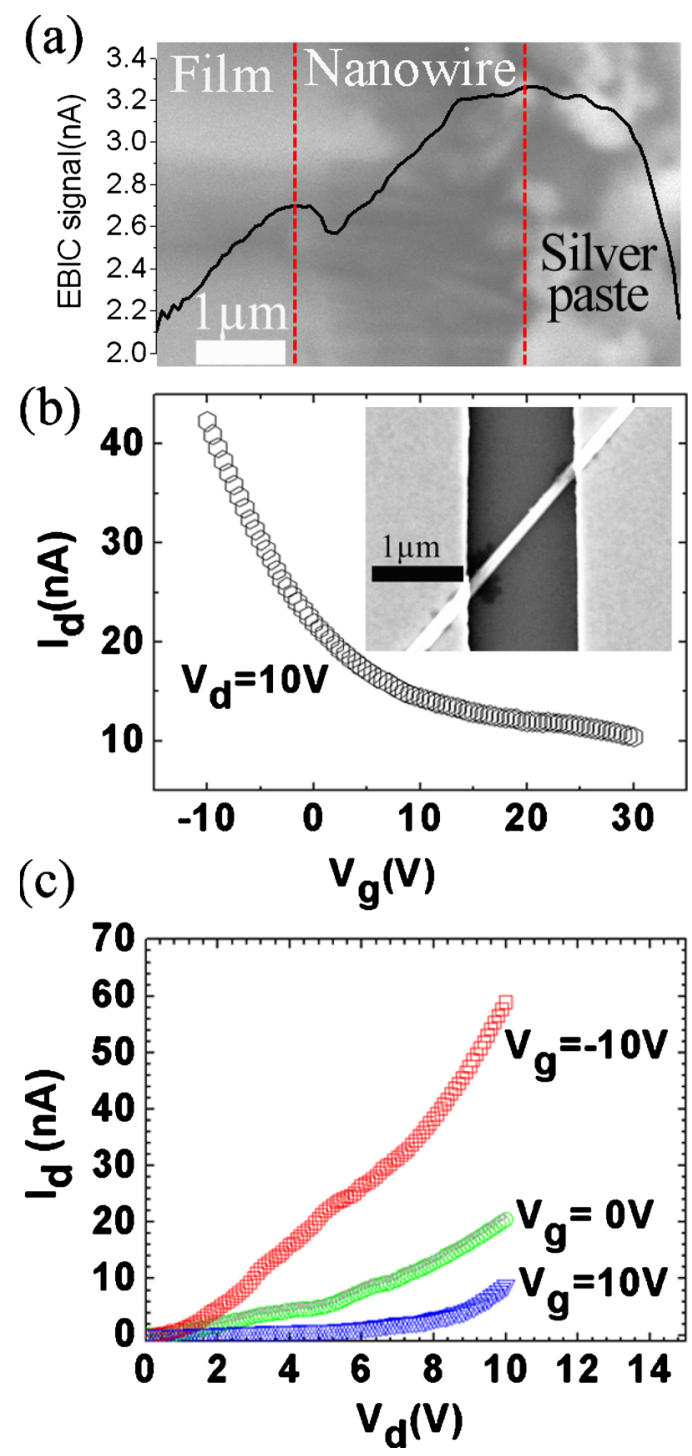

FIG. 3. (Color online) (a) EBIC profile of the device. A clear peak can be seen in the area between the $\mathrm{ZnO}$ nanowires and $\mathrm{ZnO}$ film, representing the formation of junction. (b) $\mathrm{I}_{\mathrm{d}}-\mathrm{V}_{\mathrm{g}}$ curve of the $\mathrm{ZnO}$ nanowire FET under $\mathrm{V}_{\mathrm{d}}$ $=10 \mathrm{~V}$. Inset shows the SEM image of the NWFET. (c) $\mathrm{I}_{\mathrm{d}}-\mathrm{V}_{\mathrm{d}}$ curves of the $\mathrm{ZnO}$ nanowire FET recorded at different gate voltages.

trodes were formed by e-beam deposition and subsequent lift-off. The $\mathrm{p}^{+}$-silicon substrate served as the backgate electrode of the transistor. The inset in Fig. 3(b) shows the SEM image of the NWFET. The drain current $\left(\mathrm{I}_{d}\right)$ versus gate voltage $\left(\mathrm{V}_{\mathrm{g}}\right)$ curve under a drain voltage $\left(\mathrm{V}_{\mathrm{d}}\right)$ of $10 \mathrm{~V}$ and $\mathrm{I}_{\mathrm{d}}$ versus $\mathrm{V}_{\mathrm{d}}$ curves under different gate voltages are shown in Figs. 3(b) and 3(c), respectively. The results show that the $\mathrm{Sb}$-doped $\mathrm{ZnO}$ nanowires exhibit p-type behavior under gate voltage ranging from -10 to $30 \mathrm{~V}$. The origination of the p-type conductivity of the $\mathrm{Sb}$-doped $\mathrm{ZnO}$ nanowires is from the shallow acceptors formed by substitutional $\mathrm{Sb}_{\mathrm{Zn}}$ simultaneously connecting two $\mathrm{Zn}$ vacancies. ${ }^{22}$ The hole concentration $(\mathrm{P})$ in nanowires can be estimated by using the following equation: ${ }^{23}$

$$
\mathrm{P}=\left(\frac{\mathrm{V}_{\mathrm{th}}}{\mathrm{q}}\right)\left[\frac{2 \pi \varepsilon_{\mathrm{r}} \varepsilon_{\mathrm{o}}}{\ln (4 \mathrm{~h} / \mathrm{d})}\right]\left(\frac{1}{\pi \mathrm{d}^{2} / 4}\right),
$$

where $\varepsilon_{\mathrm{r}}, \varepsilon_{\mathrm{o}}, \mathrm{h}, \mathrm{d}, \mathrm{V}_{\mathrm{th}}$, and $\mathrm{q}$ are the effective dielectric constant (3.9 for $\mathrm{SiO}_{2}$ ), the dielectric constant in vacuum, the thickness of dielectric layer $(300 \mathrm{~nm})$, the nanowire diameter 
(a)

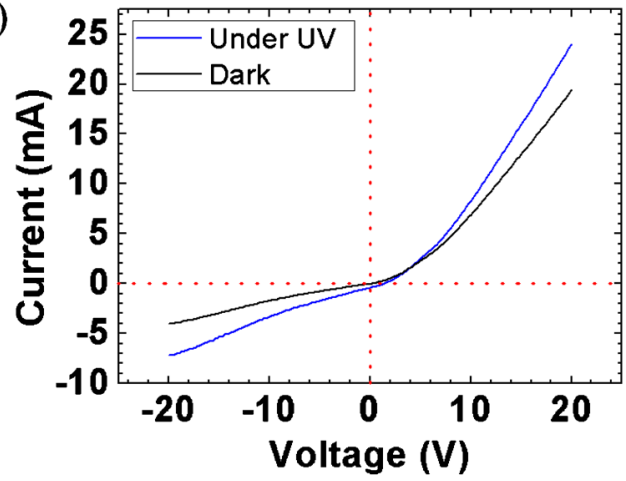

(b)

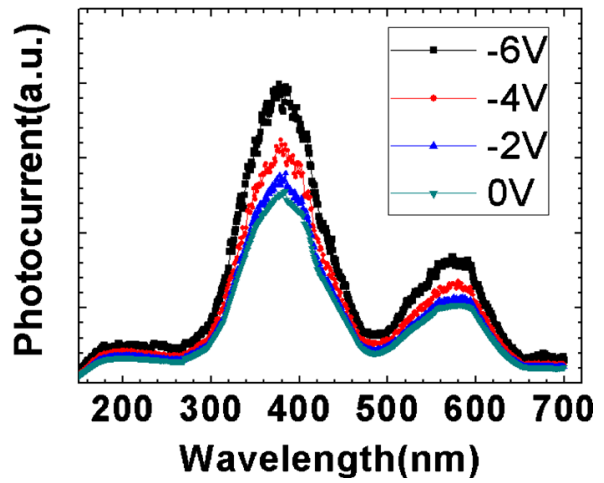

FIG. 4. (Color online) (a) I-V characteristics of the $\mathrm{ZnO}$ nanowire/ $\mathrm{ZnO}$ film device with and without UV illumination. (b) PC spectra under different reverse biases. Good responses in the UV region are evident.

$(\sim 200 \mathrm{~nm})$, the threshold voltage of the ZnO NWFET $(\sim 29 \mathrm{~V})$, and the elementary charge constant, respectively. From Eq. (1), the hole concentration is calculated to be 6.9 $\times 10^{17} \mathrm{~cm}^{-3}$. The mobility can be calculated by using the equation $^{23}$

$$
\mu=\left(\frac{\mathrm{dI}}{\mathrm{dV}_{\mathrm{g}}}\right)\left[\frac{\ln \left(\frac{4 \mathrm{~h}}{\mathrm{~d}}\right)}{2 \pi \varepsilon_{\mathrm{r}} \varepsilon_{\mathrm{o}}}\right]\left(\frac{\mathrm{L}}{\mathrm{V}_{\mathrm{d}}}\right),
$$

where $\mu, \mathrm{L}$, and $\mathrm{V}_{\mathrm{d}}$ are the mobility, the channel length $(\sim 1.8 \mu \mathrm{m})$, and the drain-source voltage $(10 \mathrm{~V})$, respectively. $\mathrm{dI} / \mathrm{dV}_{\mathrm{g}}=2.55 \mathrm{e}-009 \mathrm{~A} / \mathrm{V}$ can be extrapolated from the linear region of the $I_{d^{-}} V_{g}$ curve. From Eq. (2), the mobility is calculated as approximately $0.037 \mathrm{~cm}^{2} \mathrm{~V}^{-1} \mathrm{~s}^{-1}$ based on the experimental data.

Figure 4(a) shows current-voltage characteristics of the $\mathrm{ZnO}$ p-n homojunction. Clear rectifying behavior can be observed with and without UV illumination. The turn-on voltage is at $\sim 3 \mathrm{~V}$. The possible formation of the graded $p-n$ junction due to the impurity diffusion during nanowire growth and the formation of the metal/semiconductor nanowire contact are the reasons for the small rectification ratio of the p-n homojunction. Photocurrent (PC) measurements were carried out using a homebuilt system. The PC system consists of an Oriel Xe arc lamp as the UV source. The light from the lamp passes through an Oriel $0.25 \mathrm{~m}$ monochromator, which produces a specific wavelength light at its output port. After chopping, the light is then cast on the device. The generated PC signal is fed to a lock-in amplifier from where the data are collected. Figure 4(b) shows PC spectra of the homojunction device operated in the photovoltaic mode and also under different reverse biases. The device shows response as a result of the photocarriers generated by the absorption of light in the space-charge region. The response extends from $280 \mathrm{~nm}$ and steadily increases up to $380 \mathrm{~nm}$ $(3.26 \mathrm{eV})$, which corresponds to the effective band gap of $\mathrm{ZnO}$. The magnitude of photocurrent increases with the increase of applied reverse bias $(-2,-4$, and $-6 \mathrm{~V})$ due to enhanced carrier collection. There is a small peak at $570 \mathrm{~nm}$ $(2.17 \mathrm{eV})$ in the spectra due to the presence of deep levels in $\mathrm{ZnO}$.

In summary, $\mathrm{ZnO}$ p-n homojunctions based on Sb-doped p-type nanowire arrays and n-type thin films were grown by the combination of CVD and MBE. The $\mathrm{ZnO}$ thin film/ nanowire $p-n$ junction was proved by EBIC profiling, I-V measurement, and field-effect measurement. Evident photoresponse was observed in the UV region of the PC spectra. This study not only proved that $\mathrm{Sb}$ doping can lead to p-type $\mathrm{ZnO}$ nanowires, but also demonstrated an ultraviolet homojunction photodetector device based on p-type nanowire array and n-type thin film.

Guoping Wang and Sheng Chu contributed equally to this work. This research was partly supported by National Science Foundation (Grant No. ECCS-0900978).

${ }^{1}$ E. O. Kane, Phys. Rev. B 18, 6849 (1978).

${ }^{2}$ C. Klingshirn, Phys. Status Solidi B 244, 3027 (2007).

${ }^{3}$ D. C. Look, Mater. Sci. Eng., B 80, 383 (2001).

${ }^{4}$ S. Chu, J. H. Lim, L. J. Mandalapu, Z. Yang, L. Li, and J. L. Liu, Appl. Phys. Lett. 92, 152103 (2008).

${ }^{5}$ H. Cao, Y. G. Zhao, H. C. Ong, S. T. Ho, J. Y. Dai, J. Y. Wu, and R. P. Chang, Appl. Phys. Lett. 73, 3656 (1998).

${ }^{6}$ S. F. Yu, C. Yuan, S. P. Lau, W. I. Park, and G. Yi, Appl. Phys. Lett. 84, 3241 (2004).

${ }^{7}$ S. Chu, M. Olmedo, Z. Yang, J. Y. Kong, and J. L. Liu, Appl. Phys. Lett. 93, 181106 (2008).

${ }^{8}$ L. J. Mandalapu, F. X. Xiu, Z. Yang, D. T. Zhao, and J. L. Liu, Appl. Phys. Lett. 88, 112108 (2006).

${ }^{9}$ L. J. Mandalapu, Z. Yang, F. X. Xiu, D. T. Zhao, and J. L. Liu, Appl. Phys. Lett. 88, 092103 (2006).

${ }^{10}$ L. J. Mandalapu, F. X. Xiu, Z. Yang, and J. L. Liu, Solid-State Electron. 51, 1014 (2007).

${ }^{11}$ C. H. Chen, S. J. Chang, S. P. Chang, M. J. Li, I. C. Chen, T. J. Hsueh, and C. L. Hsu, Appl. Phys. Lett. 95, 223101 (2009).

${ }^{12}$ O. Lupan, T. Pauporte, and B. Viana, Adv. Mater. 22, 3298 (2010)

${ }^{13}$ X. M. Zhang, M. Y. Lu, Y. Zhang, L. J. Chen, and Z. L. Wang, Adv. Mater 21, 2767 (2009).

${ }^{14}$ C. G. Van de Walle, Phys. Rev. Lett. 85, 1012 (2000).

${ }^{15}$ D. K. Hwang, H. S. Kim, J. H. Lim, J. Y. Oh, J. H. Yang, S. J. Park, K. K. Kim, D. C. Look, and Y. S. Park, Appl. Phys. Lett. 86, 151917 (2005).

${ }^{16}$ K. K. Kim, H. S. Kim, D. K. Hwang, J. H. Lim, and S. J. Park, Appl. Phys. Lett. 83, 63 (2003).

${ }^{17}$ T. S. Jeong, M. S. Han, C. J. Youn, and Y. S. Park, J. Appl. Phys. 96, 175 (2004)

${ }^{18}$ F. X. Xiu, Z. Yang, L. J. Mandalapu, D. T. Zhao, and J. L. Liu, Appl. Phys. Lett. 87, 152101 (2005).

${ }^{19}$ L. E. Greene, M. Law, D. H. Tan, M. Montano, J. Goldberger, G. Somorjai, and P. D. Yang, Nano Lett. 5, 1231 (2005).

${ }^{20}$ L. Chernyak, C. Schwarz, E. S. Flitsiyan, S. Chu, J. L. Liu, and K. Gartsman, Appl. Phys. Lett. 92, 102106 (2008).

${ }^{21}$ S. Hoffmann, J. Bauer, C. Ronning, Th. Stelzner, J. Michler, C. Ballif, V. Sivakov, and S. H. Christiansen, Nano Lett. 9, 1341 (2009).

${ }^{22}$ S. Limpijumnong, S. B. Zhang, S. H. Wei, and C. H. Park, Phys. Rev. Lett. 92, 155504 (2004).

${ }^{23}$ R. Martel, T. Schmidt, H. R. Shea, T. Hertel, and Ph. Avouris, Appl. Phys. Lett. 73, 2447 (1998). 